\section{Adult-Type Intrathoracic Xanthogranuloma: Excision and Reconstruction Using a Latissimus Dorsi Muscle Flap}

Seung Han Song ${ }^{1}$, Hyunwoo Kyung ${ }^{2}$, Nakheon Kang ${ }^{1}$, Sang-Ha Oh${ }^{1}$, Kyung-Hee Kim ${ }^{3}$

${ }^{1}$ Department of Plastic and Reconstructive Surgery, Chungnam National University Hospital, Daejoen; ${ }^{2}$ Okcheon-gun Health Center, Okcheon; ${ }^{3}$ Department of Pathology, Cancer Research Institute, Chungnam National University School of Medicine, Daejoen, Korea

Correspondence: Hyunwoo Kyung

Okcheon-gun Health Center, 10 Samyang-ro 8-gil, Okcheon-eup,

Okcheon-gun 373-809, Korea

Tel: +82-43-730-2021, Fax: +82-43-730-2012, E-mail: hwkyung@gmail.com

No potential conflict of interest relevant to this article was reported.

Received: 7 Jun 2013 • Revised: 9 Jul 2013 • Accepted: 20 Jul 2013 pISSN: 2234-6163 • elSSN: 2234-6171

http://dx.doi.org/10.5999/aps.2014.41.1.96 • Arch Plast Surg 2014;41:96-98

Copyright (C) 2014 The Korean Society of Plastic and Reconstructive Surgeons

This is an Open Access article distributed under the terms of the Creative Commons

Attribution Non-Commercial License (http://creativecommons.org/licenses/by-nc/3.0/) which permits unrestricted non-commercial use, distribution, and reproduction in any medium, provided the original work is properly cited.

Xanthogranuloma (XG) is a benign and usually asymptomatic disease. It shows a self-limited etiology. Red, yellow, or brown papules and nodules composed of histiocytic cells appear on the skin [1]. This disease usually occurs at birth or within the first year of birth; however, it can occur in adults as well. The extracutaneous type of XG with no skin lesions is rare [2].

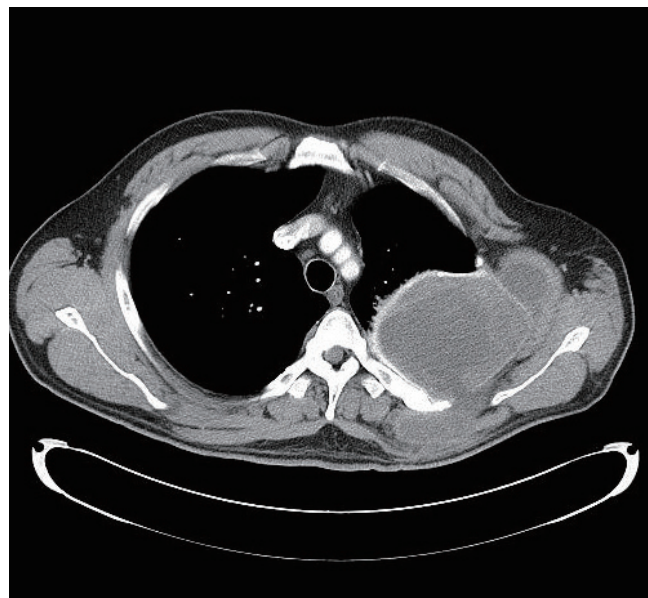

Fig. 1.

Preoperative computed tomography scan. Loculated fluid collections protruded into the left lateral chest wall and posterior back

$(12.8 \mathrm{~cm} \times 8.0 \mathrm{~cm})$.

The most common location for extracutaneous XG lesions is on the eyes, although other locations including the lung, kidney, central nervous system, colon, pericardium, ovary, liver, and spleen have been reported as well [2]. Therefore, we report our successful restoration of a huge intrathoracic dead space after excision of an extracutaneous adult XG using a latissimus dorsi (LD) muscle flap.

A 35-year-old male visited the hospital with a complaint of painful swelling around the incision site of a thoracotomy performed earlier. According to his

Fig. 2.

Histopathological examination revealed dense granulomatous infiltrates consisting of histiocytes,

lymphocytes, and a few Touton-type giant cells $\left(H \& E_{1} \times 100\right)$.

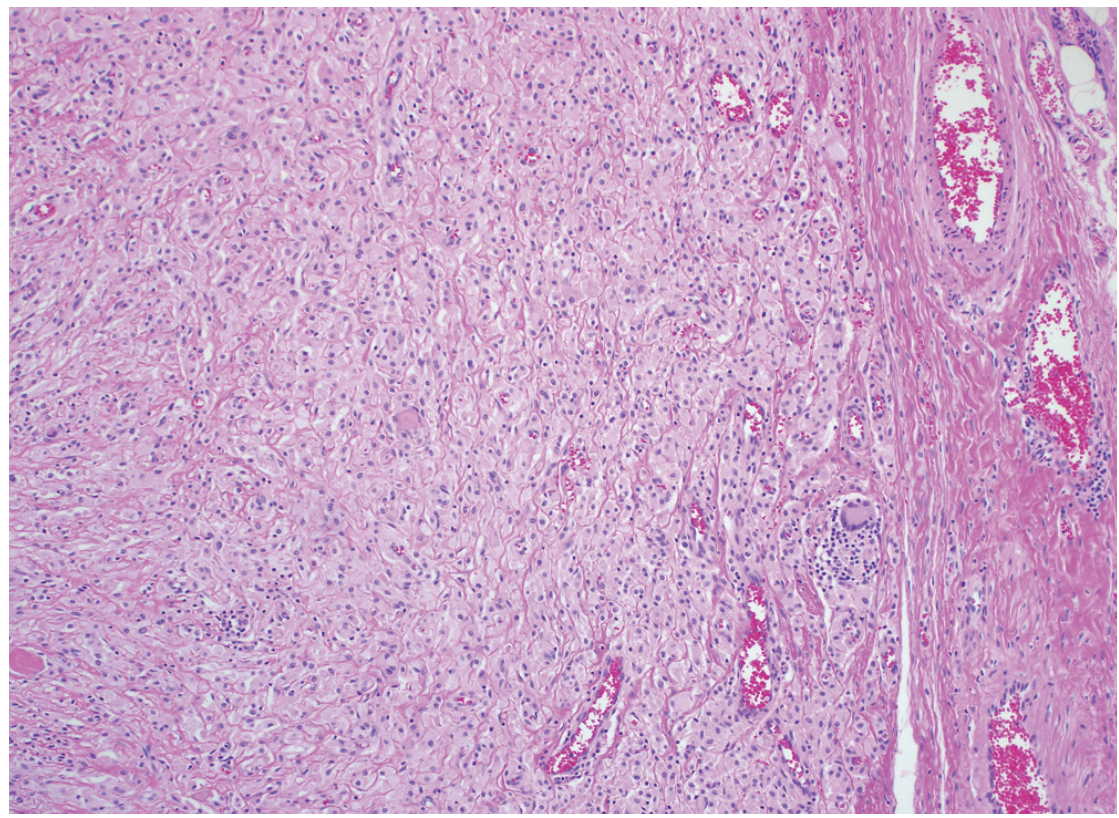


medical history, a right postero-lateral thoracotomy had been performed 16 years earlier in the hospital's Thoracic and Cardiovascular Surgery Department to remove a mass through the fourth intercostal space due to angiomyxoma. Based on a computed tomographic (CT) scan and a biopsy, the swelling was diagnosed as XG (Figs. 1, 2). At the site, a new tumor had occurred. The mass was removed through the previous thoracotomy incision site. Because a large volume defect was found to run vertically below the inferior angle of the scapula to the apical cavity of the thorax and beside the lateral border of the spine to the subcutaneous tissue and skin after the mass excision, it was decided to apply a muscle flap by LD muscle transposition.

The LD muscle was first completely elevated from the chest wall, and then, the thoracodorsal artery, which is a main pedicle, was dissected (Fig. 3). The LD muscle was transposed to the defect site with the pedicle as a pivot point through the area from which the third rib was removed for thoracotomy and the fourth intercostal space. The flap was extended to the apical cavity of the thorax to be positioned and was tightly anchored. To prevent fluid collection, a drain was applied, and the skin incision was closed. There were no postoperative wound complications such as infection or dehiscence, nor was there any fluid collection. There was no functional disability at the donor site. The scar at the incision site was relatively acceptable. A CT scan was taken 6 months after surgery, the flap was maintained relatively well, and there were no complications, although the volume of muscle had reduced slightly (Fig. 4).

$\mathrm{XG}$, which is typically a non-Langerhans histiocytosis, is found at birth in around $35 \%$ of the cases and within the first year in approximately $71 \%$ of the cases. Such cases are known as juvenile xanthogranuloma (JXG) [1]. However, around $10 \%$ to $30 \%$ cases occur in adults. Such cases appear as skin lesions only in around $81 \%$ of adult patients, while cases of extracutaneous lesions are very unusual, at 3.9\% [2]. Solitary cutaneous cases of JXG have resolved spontaneously at the remaining hyperpigmented and atrophic sites. However, treatments with steroids, vincristine, vinblastine, and 5-fluorouracil or surgical excision may be required in the case of adult forms, multiple lesions, and systemic involvement [1]. The present case was extracutaneous adult XG, and total excision was performed because conservative treatment was impossible due to severe fluid collection and pain. In addition, the resulting intrathoracic dead

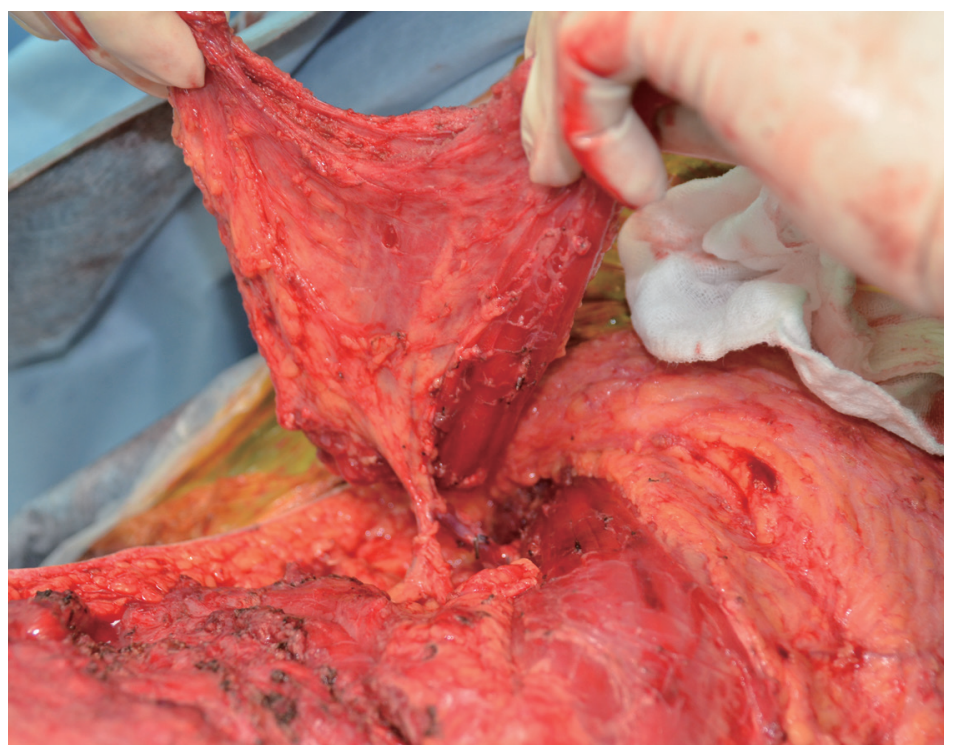

Fig. 3.

Intraoperative images. The mobilized latissimus dorsi muscle flap $(26 \mathrm{~cm} \times 17 \mathrm{~cm})$. The main pedicle was preserved.

space was restored.

A specific restoration is not necessary for a simple dead space in the pleura because of pulmonary expansion; however, an intrathoracic flap should be used for the fistula and the dead space between the bronchus, trachea, esophagus, and pleural cavity after surgery for chronic empyema or cancer. To restore a small-volume defect, a flap is raised from the diaphragm, the pericardium, the pleura, or the intercostal muscle. In another method, the omentum is transposed from the abdominal cavity through the subcutaneous tunnel to cover the defect [3]. However, for the obliteration of a high-volume defect, transposition of the serratus anterior (SA) muscle or the LD muscle must be performed [4]. In the present case, because the dead space was too large to be filled by lung expansion, an intrathoracic muscle flap from the LD muscle was used to restore a huge intrathoracic dead space after the operation.

The blood supply for the SA muscle comes from the terminal branches of the thoracodorsal artery, which is raised from the subscapular branch of the axillary artery. The blood for the LD muscle is supplied from the thoracodorsal artery as well. Arnold and Pairolero [4] reported that intrathoracic transposition can be simple if accompanied by an effective division from the chest wall attachment because it was possible to transpose the SA and the LD muscles through a thoracotomy site with a large, dominant blood supply, 
Six-month postoperative computed tomography scan.

Although the volume of the muscle had decreased, the flap was maintained relatively well.

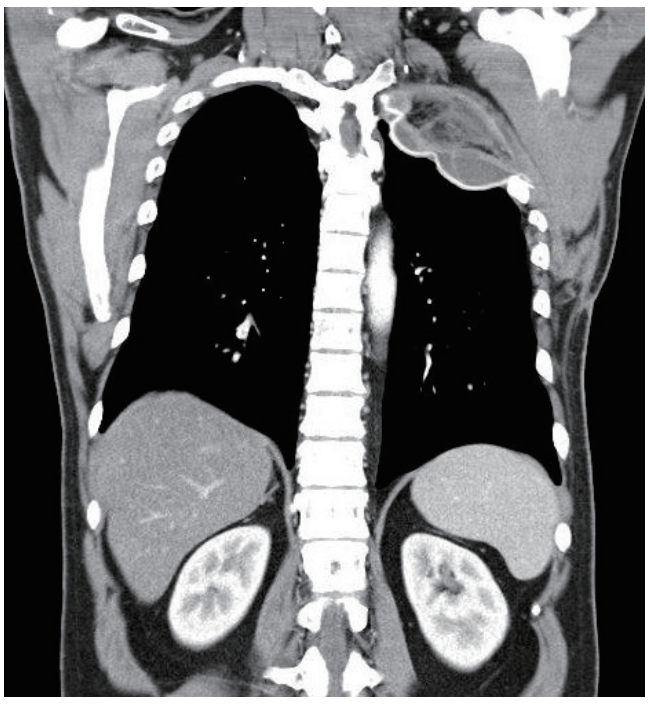

and the SA and the LD muscles were appropriate for the obliteration of the intrathoracic defect. According to Widmer et al. [5], in SA and LD muscle transpositions, the postoperative morbidity and long-term sequelae at donor sites were comparable with the two types of flaps, and the functional outcomes and quality of life were acceptable for both.

However, because the LD muscle is larger than the SA muscle, an extension to any part of the thoracic cavity is possible, and thus, the LD muscle can be used for a high-volume defect. Furthermore, functional defects at the donor site are uncommon after a harvest. On the other hand, if the entire SA muscle is harvested, scapula winging could occur. Arnold and Pairolero [4] reported that discomfort and patient dissatisfaction resulted from winging symptoms even after a subtotal scapular resection if the winging was severe. Thus, it was shown that cosmetic or functional defects are less severe with the LD muscle than the SA.

In summary, in cases of a high-volume defect extending up to the apex of the thoracic cavity, as in the case presented here, the LD muscle flap could be successfully applied to intrathoracic transposition.

\section{References}

1. Helwig EB, Hackney VC. Juvenile xanthogranuloma (nevoxantho- endothelioma). Am J Pathol 1954;30:6256.

2. Sueki H, Saito T, Iijima M, et al. Adult-onset xanthogranuloma appearing symmetrically on the ear lobes. J Am Acad Dermatol 1995;32:372-4.

3. Hollaus PH, Huber M, Lax F, et al. Closure of bronchopleural fistula after pneumonectomy with a pedicled intercostal muscle flap. Eur J Cardiothorac Surg 1999; 16:181-6.

4. Arnold PG, Pairolero PC. Intrathoracic muscle flaps: an account of their use in the management of 100 consecutive patients. Ann Surg 1990;211:656-60.

5. Widmer MK, Krueger T, Lardinois D, et al. A comparative evaluation of intrathoracic latissimus dorsi and serratus anterior muscle transposition. Eur J Cardiothorac Surg 2000;18:435-9.

\section{Bipartite os Centrale Carpi in a Patient with the First Metacarpal Bone Fracture}

Soo Chung Hong, Eun Soo Park, Seung Min Nam

Department of Plastic and Reconstructive Surgery, Soonchunhyang University College of Medicine, Bucheon, Korea

Correspondence: Eun Soo Park

Department of Plastic and Reconstructive, Soonchunhyang University Bucheon Hospital, Soonchunhyang University College of Medicine, 170 Jomaru-ro, Wonmi-gu, Bucheon 420-767, Korea

Tel: +82-32-621-5315, Fax: +82-32-621-5316

E-mail: peunsoo@schmc.ac.kr

No potential conflict of interest relevant to this article was reported.

Received: 16 Jun 2013 • Revised: 16 Oct 2013 • Accepted: 17 Oct 2013 pISSN: 2234-6163 • elSSN: 2234-6171

http://dx.doi.org/10.5999/aps.2014.41.1.98 • Arch Plast Surg 2014;41:98-100 Copyright (C) 2014 The Korean Society of Plastic and Reconstructive Surgeons This is an Open Access article distributed under the terms of the Creative Commons Attribution Non-Commercial License (http://creativecommons.org/licenses/by-nc/3.0/ which permits unrestricted non-commercial use, distribution, and reproduction in any which permits unrestricted non-commercial use, dist
medium, provided the original work is properly cited.

The os centrale carpi is a relatively rare accessory carpal bone. It is located in the carpus among the capitate, a scaphoid, and trapezoid bones. This rare anomaly is believed to represent a remnant of a separate ossification center present in the human embryo at 6 weeks of gestation that normally fuses with the scaphoid. It seem to occur as isolated anatomic variants with an incidence of 0.3 to 1.6 percent [1]. This report describes a case of a bipartite os centrale carpi in a patient who was hospitalized for a fracture of his first metacarpal bone, separately presenting as focal tenderness of the wrist and dorsoradial area. A 15-year-old male was hospitalized for painful swelling on his left hand after falling. He was diagnosed with a first metacarpal bone fracture based on plain radiographic imaging. Coincidentally, small triangular bony fragments were seen at the distal 